Real Life Cryptology 



\section{Real Life Cryptology}

Ciphers and Secrets in Early Modern Hungary

Benedek Láng

Translated from Hungarian by Teodóra Király and Benedek Láng 
Originally published as: 'Titkosírás a kora újkori Magyarországon' 2015, ISBN 9789635069514, Balassi Kiadó, Budapest

Cover design: Coördesign, Leiden

Lay-out: Newgen / Konvertus

$\begin{array}{ll}\text { ISBN } & 9789462985544 \\ \text { e-ISBN } & 9789048536696 \\ \text { DOI } & 10.5117 / 9789462985544 \\ \text { NUR } & 685\end{array}$

\section{(6) $(1) \Theta \Theta$}

Creative Commons License CC BY NC ND

(http://creativecommons.org/licenses/by-nc-nd/3.o)

c. B. Láng / Atlantis Press B.V. / Amsterdam University Press B.V., Amsterdam 2018

Some rights reserved. Without limiting the rights under copyright reserved above, any part of this book may be reproduced, stored in or introduced into a retrieval system, or transmitted, in any form or by any means (electronic, mechanical, photocopying, recording or otherwise). 